\title{
Pedagogia de Projetos no Ensino-aprendizado de Programação de Computadores: Relato de Experiência com Alunos do Curso Técnico em Informática do IFPA - Campus Cametá
}

\author{
'José S. Ribeiro \\ Laboratório de Computação Aplicada - LCA \\ Instituto Federal do Pará - Campus de Cametá. \\ 68400-000 - Cametá - PA - Brasil \\ jose.ribeirodifpa.edu.br
}

\begin{abstract}
This article presents an experience report of the application of the pedagogy of projects in the teaching of computer programming through the development of digital games. Its main focus is to highlight this pedagogical practice as an alternative in the teaching process of computer programming. This experience involved 28 students of the Technical Course in Informatics in the subsequent modality of the Federal Institute of Education, Basic, Technical and Technological of Pará - Campus Cametá and has as a result the development of 12 software projects related to Education, Health of the Elderly and Assistive Technology.

Resumo. Este artigo apresenta um relato de experiência da aplicação da pedagogia de projetos no ensino de programação de computadores através do desenvolvimento de jogos digitais. Tendo como foco principal evidenciar esta prática pedagógica como alternativa no processo de ensino de programação de computadores. Esta experiência envolveu 28 alunos do curso Técnico em Informática na modalidade subsequente do Instituto Federal de Educação, Básica, Técnica e Tecnológica do Pará - Campus Cametá e tem como resultado o desenvolvimento de 12 projetos de software dentro das linhas Educação, Saúde do Idoso e Tecnologia Assistiva.
\end{abstract}

\section{Introdução}

$\mathrm{Na}$ matriz de cursos de nível técnico de informática as disciplinas relacionadas à programação de computadores são geralmente recebidas com dificuldades pelos discentes. Ou seja, Disciplinas como Fundamentos da Programação e Linguagem de Programação I e II, por exemplo, são consideradas complexas por muitos estudantes (MANZANO; JÚNIOR, 2014).

Tornar o ensino-aprendizado das disciplinas que trabalham programação de computadores significativo e agradável aos alunos é uma missão difícil de ser cumprida, devido a grande quantidade de conteúdo teórico necessário para execução de aulas práticas das disciplinas (JUNIOR; NAKAMITI; ENGELBRECHT, 2012).

Comumente, até mesmo professores na área de desenvolvimento de software concordam que disciplinas de linguagens de programação apresentam peculiaridades em seus processos de ensino-aprendizado. Aspectos estes que definem o sucesso do docente e da turma para com o entendimento dos assuntos (DEITEL; DEITEL, 2010)

Tópicos como "Programação em Java" ou "Programação C/C++", por exemplo, são partes dos conteúdos vistos na disciplina Linguagem de Programação, sendo encarados muitas vezes com elevada dificuldade por parte dos estudantes, gerando assim altos índices de reprovações. Este problema, muitas vezes está ligado a aspectos 
como: a forma que o aluno é introduzido à disciplina, desinteresse do aluno, a forma de ensino do professor, a disposição e disponibilidades dos laboratórios utilizados em aulas práticas, deficiências em diferentes níveis de formação por parte do aluno, entre outros (GOMES, 2010).

O desenvolvimento de novas proposta metodológicas que permitam ao aluno compreender os numerosos conceitos teóricos necessários para que este os utilize nas aulas práticas é um desafio enfrentado por professores da área de informática, já que muitas vezes este problema está ligado diretamente ao tempo de aprendizagem de cada discente juntamente com o tempo de duração das disciplinas (DEITEL; DEITEL, 2010).

\subsection{Referencial Teórico}

Existem iniciativas, como em (KHANACADEMY, 2018), que buscam aplicar o ensino de programação de computadores nas séries fundamentais a fim de permitir o prévio contato de estudantes com esta área de conhecimento.

Estudos como (GOMES, 2010) reforçam ainda mais os problemas enfrentados por professores e alunos na disciplina de Programação de Computadores ou mesmo Linguagem de Programação, buscando apontar alternativas ferramentais que visem viabilizar o processo do ensino aprendizado do aluno.

$\mathrm{Na}$ maioria das instituições de ensino, disciplinas voltadas para a programação de computadores são baseadas em aulas teóricas e práticas, onde normalmente usa-se a avaliação continuada do aluno, muitas vezes baseado na aplicação de atividades individualizada do aluno (SILVA; SANTOS, 2006).

A Avaliação Continuada (BRASIL, 2018) é uma estratégia necessária para o processo de ensino-aprendizagem do aluno, porém em muitos casos é pouco explorada pelos docentes, uma vez que estes normalmente aplicam esta forma de avaliação no formato de "atividade, trabalho e prova" de maneira simplificada e inflexível. Muitas vezes, inclusive, não agregando este tipo de avaliação com outras práticas de ensino, como por exemplo pedagogia de projetos.

O termo pedagogia de projetos, apesar de ser atualmente muito difundido e defendido por escolas, não é considerado um termo novo, como pode ser visto abaixo:

Embora a "Pedagogia de Projetos" esteja, atualmente, revestida de uma aura de novidade, parte de sua trajetória já completou um século de existência. Certamente, não nasceu com o arcabouço teórico/prático de que hoje dispõe; afinal, à medida que passou a ser objeto de estudos e análises, foram incorporando-se inúmeras interpretações e contornos, de acordo com o vaivém das ondas desse tão revolto século $X X$, marcado por realidades históricas essencialmente paradoxais e emblemáticas no que se refere à quebra de paradigmas em todos os setores da sociedade (FLECK, 2005).

Pedagogia de projetos é um conceito importante que pode servir como estratégia aplicável no processo de ensino-aprendizado de programação de computadores, o referido termo é baseado na ideia de educação democrática defendida por Jhon Dewey (DEWEY, 2010).

Segundo Maria Prado em estudo realizado em 2009, na pedagogia de projetos o aluno aprende inserido no processo de produzir, ou seja, levantando dúvidas, pesquisando e criando relações, que os incentivaram em novas buscas e também descobertas, sempre em busca da compreensões e reconstruções de conhecimento. Buscando mudar a proposta de um professor como somente um transmissor de conhecimento e colocando-o como um mediador de situações de aprendizagem, onde o mesmo ajudará o aluno a encontrar sentido na atividade que está executando (PRADO, 2009). 
A pedagogia de projetos vêm ganhando cada vez mais destaque como prática de ensino, pois estabelece relações das informações que o aluno já detêm ou mesmo possui acesso, com as informações que ele deve ser capaz de aprender. (SILVA; PAIVA, 2017).

A mediação pedagógica se faz necessária através do acompanhamento, por parte do docente, durante todo o processo da aplicação da prática de pedagogia de projetos, pois como descrito anteriormente, o professor precisa auxiliar o aluno a entender que caminho seguir para alcançar seu objetivo (PRADO, 2009).

Diante deste contexto, esta pesquisa surge com o relato de experiência da estratégia metodológica utilizada no ensino de programação de computadores, baseada em avaliação continuada e pedagogia de projetos utilizada pelo autor desta pesquisa durante um semestre como professor da disciplina de Linguagem de Programação I em curso Técnico de Informática Subsequente do Instituto Federal de Educação Básica, Técnica e Tecnológica do Pará - IFPA Campus Cametá.

\section{Metodologia}

O estudo de caso aqui descrito ocorreu com duas turmas do IFPA Campus Cametá, no curso Técnico de Informática na modalidade subsequente com um total de 28 alunos, em sua maioria, estudantes originados de famílias de baixa renda e de descendência ribeirinha da região do Baixo Tocantins (nordestes do Pará).

O objeto de estudo desta pesquisa está inserido em uma temática de elevada discursão entre docentes que atuam com disciplinas relacionadas a programação de computadores, ou seja, "Como ensinar programação de computadores a alunos que nunca antes se depararam com tal assunto?".

Em meio a dificuldades no processo de ensino-aprendizado de programação de computadores, muitos docentes acabam recorrendo a formas descontextualizadas de como ensinar, ou seja, não levam em consideração o perfil do aluno com que eles estão trabalhando, gerando com isso, autos índices de reprovações e até mesmo resistências e desistências por parte dos alunos (GOMES, 2010).

O utilizado pela pedagogia de projetos desta pesquisa se fundamenta na exploração de conhecimentos já familiares para os discentes, levando-se em consideração a contextualização destes, para assim tornar mais acessível o entendimento de conceitos complexos e desconhecidos, que neste caso são os conhecimentos presentes na disciplina de Linguagem de Programação I.

Iniciando a aplicação da pedagogia de projetos aqui defendida, foi realizado um movimento de escuta com os discentes, no início do semestre, com o objetivo de se identificar qual o conhecimento relacionado a software era mais familiar a maioria dos alunos. Este momento se resumiu em uma conversa em sala de aula entre o docente e os discentes.

Neste movimento de escuta foram apresentados 5 tipos de projetos que poderiam vir a ser desenvolvidos durante o semestre, porém precisava-se verificar a afinidade dos alunos com cada um destes. Os tipos de software apresentados foram:

- Aplicativos: softwares voltados para as mais diferentes finalidades, porém todos relacionados a tarefas específicas de um usuário comum de computador;

- Educacionais: softwares voltados para atividades educativas de seu usuário, onde objetivo principal é aprender/ensinar sobre um assunto específico;

- Ferramentas administrativas: softwares voltados para facilitar atividades de usuários de computadores em tarefas específicas de uma empresa/instituição;

- Jogos Digitais: softwares relacionados aos mais diferentes tipos de jogos digitais simples presentes na nossa atualidade; 
- Simulações: softwares voltados a realizações de simulações referentes a problemas das mais diferentes naturezas a serem executadas através de virtualizações.

Ao fim do movimento de escuta houveram 5 consultas aos alunos (uma para cada tipo de software), onde observou-se uma elevada aceitação dos discentes a softwares do tipo "Jogos Digitais". Para comparações com as demais categorias, observe a distribuição apresentada no Figura 1.

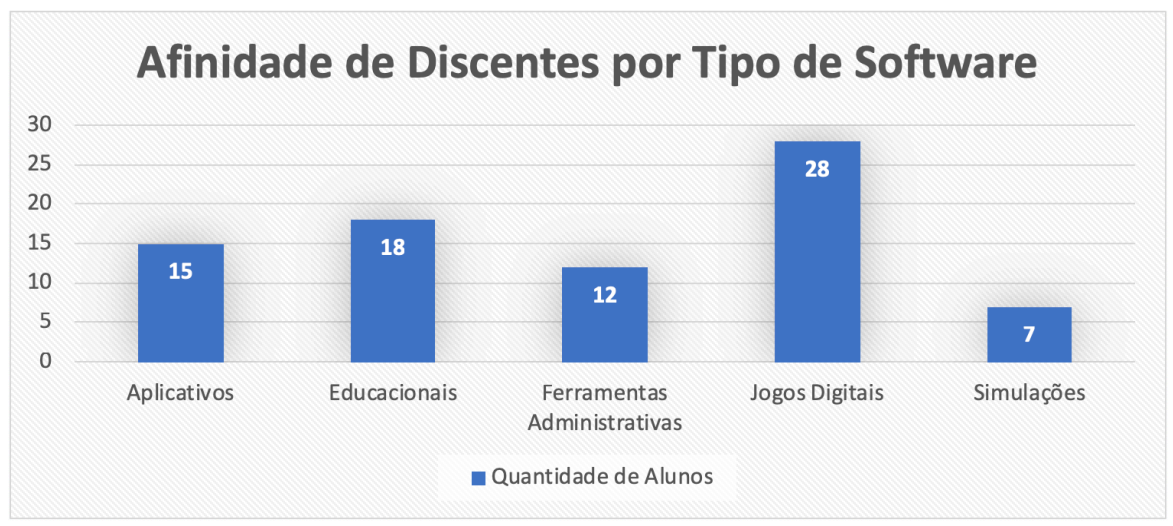

Figura 1 - Neste gráfico são apresentados os quantitativos de alunos que apresentam afinidades com cada um dos temas de softwares. Note que os 28 alunos envolvidos nesta pesquisa apresentam afinidade com softwares do tipo “Jogos Digitais”. Fonte: Autores.

Após a definição do tipo de software a ser desenvolvido, foram sugeridos possíveis temas de jogos que os alunos seguiriam, também foram feitas explanações sobre a forma de desenvolvimento do programa que a turma deveria seguir.

Em seguida o docente informou aos alunos que o processo de desenvolvimento do software objeto da pedagogia de projetos em questão deveria ser desenvolvido pelos alunos ao decorrer de todo o semestre. Ressaltando-se que durante o decorrer de toda a disciplina iriam ocorrer acompanhamentos do que fosse desenvolvido pelos alunos, isto a cada finalização de um tópico da disciplina.

Para melhor entendimento sobre os tópicos da disciplina em questão, a seguir estes são apresentados:

- Introdução ao $J A V A$;

- Conhecendo o NetBeans:

- Preparando o ambiente;

- Entendendo um projeto Java;

- Implementações utilizando Java:

- Entendendo variáveis;

- Operadores;

- Sistema de entrada e saída de informações (System.out, Scanner e JOptionPane);

- Estrutura de Condição (if, else, aninhação e switch);

- Estrutura de Repetição (while, for);

- Vetores e Matrizes;

- Tratamento de Exceções (Try, Catch e Finally);

- Aprendendo a utilizar bibliotecas: String, ArrayList e Math. 
Em cada orientação o docente responsável pela disciplina buscou reunir com cada uma das duplas de alunos (durante 5 a 7 minutos) e assim verificou se estes estavam aplicando na prática os conceitos teóricos repassados nas aulas anteriores.

Vale ressaltar que o desenvolvimento de projetos, juntamente com as orientações das duplas, não substituíram o modelo de aula com explanações relacionadas aos tópicos da disciplina. Mas sim complementaram tais aulas tornando-as mais acessíveis aos alunos.

Ao total foram realizados 13 orientações durante o decorrer do semestre para cada uma das equipes. Valendo-se ressaltar que o docente ainda atendeu as equipes que estavam com dificuldades (não foram todas) em seu horário de "Atendimento Intraescolar", sendo este oferecido durante 2 horas por semana durante todo o semestre.

É importante salientar que durante todo o semestre o quesito frequência do discente foi analisado, assim como seu interesse, dedicação e domínio técnico do projeto, tornando assim a avaliação continuada, que viera a compor $100 \%$ da nota do segundo semestre. Porém vale ressaltar que a nota do primeiro semestre foi dividida entre $50 \%$ aplicação de prova e $50 \%$ avaliação continuada através da pedagogia de projetos.

\section{Resultados e Investigações}

Os resultados coletados por esta pesquisa foram adquiridos a partir da aplicação da prática da proposta aqui defendida em duas turmas do curso técnico Subsequente em Informático do Instituto Federal de Educação Básica, Técnica e Tecnológica do Pará IFPA Campus Cametá, na disciplina de Linguagem de Programação I, durante o semestre 2017.1.

As referidas turmas apresentavam juntas 28 alunos, portanto esperava-se um total de 14 projetos desenvolvidos, uma vez que a proposta defendia o desenvolvimento do projeto de software em dupla.

O formato em que a proposta de projeto foi apresentada aos alunos é apresentada no trecho abaixo.

\section{"Caro aluno, durante este semestre sua dupla deve desenvolver um jogo utilizando os conhecimentos adquiridos na disciplina de Linguagem de Programação I buscando aprimorar técnicas de desenvolvimento de software discutidas durante aulas teóricas e práticas" (Fonte: Autores).}

Foram também apresentados possíveis temas de jogos que os estudantes poderiam utilizar em seus projetos, como: Jogo da forca, Adivinhe a sequência secreta, Decore a sequência secreta, Caça palavras, Palavra cruzada, Quiz sobre tema interessante, Show do milhão, Sete erros, Ache os pares, Jogo da velha, Sudoku, Campo minado e Acerte o cálculo.

É importante enfatizar que as temáticas dos jogos foram apresentadas aos alunos, porém suas definições de contextualizações foram de total responsabilidade de cada dupla.

Deve-se também destacar que entre as 14 duplas, 2 delas tiveram problemas e acabaram não desenvolvendo seus projetos conforme o calendário previsto da disciplina. Por isso estas 2 equipes não são listadas dentre os resultados desta pesquisa.

Diante do exposto, teve-se o desenvolvimento de 12 projetos com diferentes contextualizações, Tabela 1. 
Tabela 1 - Projetos de jogos digitais desenvolvidos na disciplina Linguagem de Programação I.

\begin{tabular}{|c|c|c|}
\hline $\begin{array}{l}\text { ID } \\
\text { Projeto }\end{array}$ & Título & Objetivo \\
\hline 1 & $\begin{array}{l}\text { Proposta de Jogo da Memória } \\
\text { Desenvolvido em JAVA Voltado } \\
\text { para Pessoas com Idade } \\
\text { Avançada. }\end{array}$ & $\begin{array}{l}\text { Desenvolvimento de jogo digital desenvolvido } \\
\text { com a finalidade de propiciar o exercício da } \\
\text { memória de idosos. }\end{array}$ \\
\hline 2 & $\begin{array}{l}\text { Acerte o cálculo: Proposta de } \\
\text { Jogo Matemático para O Ensino } \\
\text { para Crianças. }\end{array}$ & $\begin{array}{l}\text { Uso de jogos desenvolvidos para trabalhar } \\
\text { assuntos específicos da disciplina de } \\
\text { matemática. Permitindo uma aprendizagem } \\
\text { significativa destes por parte de alunos do } \\
\text { ensino básico. }\end{array}$ \\
\hline 3 & $\begin{array}{l}\text { Proposta de Simulador de Urna } \\
\text { Eletrônica Direcionada aos Alunos } \\
\text { do Fundamental (5a a 8a Série) } \\
\text { como Incentivo a Prática da } \\
\text { Cidadania. }\end{array}$ & $\begin{array}{l}\text { Apresentar uma proposta de simulador de } \\
\text { urna eletrônica voltado para alunos do ensino } \\
\text { médio, como forma incentivo ao ensino de } \\
\text { boas práticas a cidadania. }\end{array}$ \\
\hline 4 & $\begin{array}{l}\text { Desenvolvimento de Jogo } \\
\text { Simples como Alternativa } \\
\text { Metodológica ao Processo de } \\
\text { Ensino Aprendizagem } \\
\text { Linguagem de Programação de } \\
\text { Computadores. }\end{array}$ & $\begin{array}{l}\text { Apresentar o desenvolvimento de um jogo } \\
\text { digital de lógica simples, como proposta } \\
\text { metodológica ao processo de ensino } \\
\text { aprendizagem da disciplina de Linguagem de } \\
\text { Programação I. }\end{array}$ \\
\hline 5 & $\begin{array}{l}\text { Estudo de Caso: Jogo Digital } \\
\text { Desenvolvido como Estratégia } \\
\text { Metodológica no Processo de } \\
\text { Ensino de Linguagem de } \\
\text { Programação de Computadores. }\end{array}$ & $\begin{array}{l}\text { O objetivo deste trabalho é apresentar uma } \\
\text { estratégia metodológica, baseada na } \\
\text { Orientação ao Problema, no processo de } \\
\text { ensino aprendizagem de linguagem de } \\
\text { programação de computadores, utilizando } \\
\text { como problema central o desenvolvimento de } \\
\text { um jogo digital Campo Minado. }\end{array}$ \\
\hline 6 & $\begin{array}{l}\text { Caça Palavras: Aplicação de Jogo } \\
\text { Caça Palavras para Avaliação de } \\
\text { Saúde Mental de Idosos. }\end{array}$ & $\begin{array}{l}\text { Estimular a memória de pessoas idosas a fim } \\
\text { de se possibilitar os benefícios da prática de } \\
\text { jogos as mesmas, a partir do Jogo Caça } \\
\text { Palavras. }\end{array}$ \\
\hline 7 & $\begin{array}{l}\text { Proposta de Jogo de Perguntas e } \\
\text { Respostas Desenvolvido em } \\
\text { JAVA como Recurso Pedagógico } \\
\text { de Professores do Ensino } \\
\text { Fundamental. }\end{array}$ & $\begin{array}{l}\text { Apresentar uma proposta de jogo de } \\
\text { perguntas e respostas desenvolvido em } \\
\text { JAVA, que possibilitará ao docente configurar } \\
\text { seu conteúdo de acordo com os assuntos por } \\
\text { ele trabalhado, servido assim como recurso } \\
\text { pedagógico principalmente para professores } \\
\text { do ensino fundamental. }\end{array}$ \\
\hline 8 & $\begin{array}{l}\text { Acerte a Sequencia Secreta: } \\
\text { Proposta de Jogo de Raciocínio e } \\
\text { Memória Voltado para Idosos. }\end{array}$ & $\begin{array}{l}\text { Apresentar uma proposta de jogo digital que } \\
\text { trabalha raciocínio e memória, desenvolvido } \\
\text { especificamente para idosos. }\end{array}$ \\
\hline 9 & $\begin{array}{l}\text { Proposta de Jogo da Velha em } \\
\text { Alto Contraste para Pessoas com } \\
\text { Deficiência Visual. }\end{array}$ & $\begin{array}{l}\text { Apresentar uma proposta de um jogo da velha } \\
\text { desenvolvido especialmente para pessoas } \\
\text { com baixa visão, baseado em interfaces de } \\
\text { alto contraste. }\end{array}$ \\
\hline 10 & $\begin{array}{l}\text { Proposta de Jogo Digital para o } \\
\text { Ensino de Lógica para Estudantes } \\
\text { do Ensino Médio Menor. }\end{array}$ & $\begin{array}{l}\text { Propor um software desenvolvido no formato } \\
\text { de "quiz", voltado para o ensino do raciocínio } \\
\text { lógico a alunos do ensino médio menor, como }\end{array}$ \\
\hline
\end{tabular}




\begin{tabular}{|c|l|l|}
\hline & & $\begin{array}{l}\text { forma de resignificar o processo de ensino } \\
\text { aprendizagem de informática }\end{array}$ \\
\hline 11 & $\begin{array}{l}\text { FastCalc - Desenvolvimento de } \\
\text { Jogo Matemático para Plataforma } \\
\text { Android. }\end{array}$ & $\begin{array}{l}\text { Um aplicativo chamado FastCalc que visa } \\
\text { auxiliar na aprendizagem dos alunos no } \\
\text { ensino da matemática promovendo desta } \\
\text { forma para os mesmos aulas mais prazerosas } \\
\text { e atrativas. }\end{array}$ \\
\hline 12 & $\begin{array}{l}\text { Proposta de Jogo Digital } \\
\text { Educacional Voltado para } \\
\text { Aprendizagem de Leitura e e } \\
\text { Escrita de Crianças do 1 } 1^{\circ} \text { ao } 5^{\circ} \\
\text { Ano do Ensino Fundamental. }\end{array}$ & $\begin{array}{l}\text { Apresentar uma proposta de jogo digital } \\
\text { educacional simples, desenvolvido com a } \\
\text { finalidade de tornar lúdico o processo de } \\
\text { ensino aprendizagem de leitura e escrita de } \\
\text { crianças do ensino fundamental menor. }\end{array}$ \\
\hline
\end{tabular}

Como é de se notar na Tabela 1, os trabalhos desenvolvidos durante a disciplina de Linguagem de Programação, apesar de serem propostas de jogos entendidas como simples, buscam resolver problemas específicos identificados por cada dupla de aluno. Com isso, observa-se que a proposta descrita por esta pesquisa alcança seu objetivo maior.

Observa-se que as propostas de projetos desenvolvidas pelos discentes podem ser agrupadas nas linhas: Saúde do Idoso (projetos: 1, 6 e 8), Educação (projetos: 2, 3, 4, 5, 7, 10, 11 e 12) e Tecnologia Assistiva (projeto: 9).

As linhas de projetos, identificadas por esta pesquisa, apresentam as preocupações dos estudantes envolvidos. Neste caso, deve-se destacar o alto número de projetos relacionados a educação. Este fato é justificado, se levado em consideração que a cidade de Cametá é considerada por muitos cidadãos como uma "Cidade para Estudantes". Com isso, muitos estudantes migram de outras cidades para Cametá, a fim de conseguir uma melhor formação.

Inserido na linha Educação, se destaca o trabalho 3, que se define como um jogo que busca simular o funcionamento de uma urna eletrônica voltada especificamente para crianças. $\mathrm{O}$ interessante neste projeto está relacionado a sua temática, pois esta não está presente dentre as sugestões apresentadas pelo docente, no início do processo de aplicação da pedagogia de projetos, o que mostra que os discentes pesquisaram novas temáticas de jogos, além das que haviam sido passadas pelo professor.

Em dialogo com as equipes que desenvolveram softwares voltados para Saúde de Idosos, foi verificado que o Centro de Idosos de Cametá apresentava problemas para utilização de seu laboratório de informática. Desta forma, entende-se que este fato incentivou aos alunos o desenvolvimento de propostas alternativas que possibilitassem, aos idosos que ali eram atendidos, a prática da informática através de jogos digitais.

A última linha de projeto existente dentre os resultados aqui apresentados foi a Tecnologia Assistiva, sendo que em dialogo com os discentes desta proposta foi verificado que inicialmente o foco do projeto era um Jogo da Velha para um usuário comum de computador. Porém, estes estudantes, verificaram que seu projeto ficava muito simples, em busca por novos desafios encontraram uma alternativa para aumentar a complexidade do software em questão (sugestão do professor da disciplina), tornando o jogo da velha voltado para pessoas com baixa visão.

\section{Conclusões}

Diante do apresentado, pode-se dizer que a pedagogia de projetos cumpre seu papel mesmo inserida no processo de ensino-aprendizado da disciplina Linguagem de Programação I, uma vez que se tem como resultado desta aplicação os desenvolvimentos de diferentes projetos de softwares voltados para diferentes problemáticas, Tabela 1. 
Dizer que a aplicação da pedagogia de projetos torna o ensino-aprendizado de linguagem de programação mais fácil vai contra as ideias apresentadas neste trabalho. Pois, no entendimento desta pesquisa a pedagogia de projetos torna o estudante mais ativo e interessado pelos conteúdos da referida disciplina.

O docente em questão relata que houve uma diferença perceptível em sala de aula quanto ao interesse dos estudantes durante as aulas teóricas e práticas da disciplina, a partir do momento que aplicou a pedagogia de projetos no formato aqui apresentado.

Esta pesquisa sugere maior possibilidade de variedade de tipos de software e mesmo temas a serem escolhidos pelos discentes, porém isso reflete diretamente na necessidade de se disponibilizar dois docentes para ministrar a disciplina, dado o alto número de orientações para cada equipe.

Uma pesquisa quantitativa sobre a visão dos alunos em estudos futuros se faz necessária, a fim de se entender a forma com que os alunos receberam e entenderam a aplicação da pedagogia de projetos em uma disciplina considerada difícil entre muitos alunos.

Contudo, o processo de avaliação continuada agregada a pedagogia de projetos, no formato aqui apresentado, cumpriu a proposta de ser uma alternativa no processo de ensino-aprendizado de programação de computadores, possibilitando assim um espaço em sala de aula voltado a resoluções de problemas, permitindo que o aluno se questiona-se "como alcançar seus objetivos diante do problema proposto", realizando assim pesquisas e estudos diversos que o levaram a desenvolver o programa proposto, superando assim o problema.

\section{Referências}

BRASIL. L9394. Disponível em: <http://www.planalto.gov.br/ccivil_03/LEIS/L9394.htm>. Acesso em: 29 set. 2018.

DEITEL, H. M.; DEITEL, P. J. Java como programar. São Paulo (SP): Pearson Prentice Hall, 2010.

DEWEY, J. Democracy and Education: an Introduction to the Philosophy of Education. Boston: MobileReference.com, 2010.

FLECK, S. Pedagogia de Projetos. Fundação CECIRJ, 2005.

GOMES, A. DE J. Dificuldades de aprendizagem de programação de computadores: contributos para a sua compreensão e resolução. p. 492, 2010.

JUNIOR, D.; NAKAMITI, G.; ENGELBRECHT, A. Algoritmos e Programação de Computadores. 1. ed. [s.1.] Elsevier Editora Ltda., 2012.

KHANACADEMY. Estudo de caso de programação: como dar uma aula no Ensino Fundamental. Disponível em: <https://pt.khanacademy.org/resources/k-12-teachers1/teaching-computing/a/programming-case-study-teaching-an-elementary-schoolclass>. Acesso em: 29 set. 2018.

MANZANO, J. A. N. G.; JÚNIOR, R. A. D. C. Java 8 - Programação De Computadores - Guia. [s.l.] ERICA, 2014.

PRADO, M. Pedagogia de projetos. p. 14, 2009.

SILVA, J.; PAIVA, S. Pedagogia de Projetos e Interdisciplinaridade: Relato de uma Experiência de Escrita Colaborativa de Livrotexto da Disciplina Segurança e Auditoria de Sistemas. IV CONEDU, 2017.

SILVA, M.; SANTOS, E. Avaliação da aprendizagem em educação online: fundamentos, interfaces e dispositivos, relatos de experiências. São Paulo: Loyola, 2006. 